\title{
Cytochrome b Mutations F129L and G143A Confer Resistance to Azoxystrobin in Cercospora nicotianae, the Frogeye Leaf Spot Pathogen of Tobacco
}

\author{
Edward Dixon, ${ }^{1}$ William Barlow, ${ }^{1}$ Grant Walles, ${ }^{2}$ Bernadette Amsden, ${ }^{1}$ R. Louis Hirsch, ${ }^{1}$ Robert Pearce, ${ }^{3}$ and Emily E. Pfeufer ${ }^{1,}$ \\ ${ }^{1}$ Department of Plant Pathology, University of Kentucky \\ ${ }^{2}$ Science, Technology, Engineering, Arts, and Mathematics Academy, Lexington, KY, U.S.A. \\ ${ }^{3}$ Department of Plant and Soil Sciences, University of Kentucky
}

\begin{abstract}
Azoxystrobin is the only synthetic, systemic fungicide labeled in the United States for management of frogeye leaf spot (FLS) of tobacco ( $\mathrm{Ni}$ cotiana tabacum L.), caused by Cercospora nicotianae. Though traditionally considered a minor disease in the United States, FLS has recently become yield and quality limiting. In 2016 and 2017, $100 C$. nicotianae isolates were collected from symptomatic tobacco from eight counties in Kentucky, United States. Prior to azoxystrobin sensitivity testing, some C. nicotianae isolates were found to utilize the alternative oxidase pathway and, after assay comparisons, conidial germination was utilized to evaluate sensitivity in $C$. nicotianae as opposed to mycelial growth. Azoxystrobin sensitivity was determined by establishing the effective concentration to inhibit $50 \%$ conidial germination $\left(\mathrm{EC}_{50}\right)$ for 47 (in

Partial cytochrome $b$ sequence, encompassing the F129L and G143A mutation sites, indicated single-nucleotide polymorphisms (SNPs) conferring the F129L mutation in C. nicotianae of moderate resistance (azoxystrobin at $0.177 \leq \mathrm{EC}_{50} \leq 0.535 \mu \mathrm{g} / \mathrm{ml}$ ) and the G143A mutation in isolates with an azoxystrobin-resistant phenotype (azoxystrobin $\mathrm{EC}_{50}>1.15 \mu \mathrm{g} / \mathrm{ml}$ ) Higher frequencies of resistant isolates were identified from greenhouse transplant (4 of 17) and conventionally produced (58 of 62$)$ tobacco samples, as compared with field-grown tobacco $(<4$ weeks prior to harvest; 4 of 62 ) or organically produced samples ( 1 of 7), respectively. Together, these results suggest that resistance to azoxystrobin in $C$. nicotianae occurs broadly in Kentucky, and generate new hypotheses about selection pressure affecting resistance mutation frequencies.
\end{abstract} 2016) and 53 (in 2017) C. nicotianae isolates. Distributions of C. nicotianae $\mathrm{EC}_{50}$ values indicated three qualitative levels of sensitivity to azoxystrobin.
Keywords: chemical, field crops, disease management, fungi
Frogeye leaf spot (FLS), caused by Cercospora nicotianae Ellis \& Everh., has historically been considered a minor foliar disease restricted to older tobacco (Nicotiana tabacum L.) tissue in the lower canopy (Lucas 1975). Lesions are typically 1 to $1.5 \mathrm{~cm}$ in diameter, with a chlorotic halo surrounding a red-brown necrotic ring. Lesion centers are tan and, under humid conditions, pseudostromata, short conidiophores, and conidia develop (Supplementary Fig. S1). The disease was traditionally considered so minor that FLS in lowercanopy leaves was desirable to some tobacco buyers, indicating that the crop reached full maturity in the field (Lucas 1975). However, since approximately 2015, FLS has vastly increased in incidence and severity, resulting in price dockage or outright rejection due to reduced quality (Bickers 2016a,b,c,d, 2017, 2018; Fowlkes 2016, 2017) (personal communication). This also coincided with the first documentation of FLS occurring in greenhouse-produced tobacco transplants (Dixon et al. 2018). Although demand for U.S.-produced tobacco has steadily decreased over the past few decades, the U.S. crop was still worth over $\$ 1.4$ billion dollars in 2017 (USDA-NASS 2018). Kentucky is the leading U.S. producer of burley and dark tobacco, two subtypes of tobacco utilized in different consumer product blends. Although some growth in organic tobacco production has

${ }^{\dagger}$ Corresponding author: E. E. Pfeufer; epf222@uky.edu

Funding: Funding was provided by the College of Agriculture, Food, and the Environment at the University of Kentucky as well as the Council for Burley Tobacco.

*The $\boldsymbol{e}$-Xtra logo stands for "electronic extra" and indicates that one supplementary figure is published online.

The author(s) declare no conflict of interest.

Accepted for publication 13 January 2020.

(C) 2020 The American Phytopathological Society occurred in recent years, the authors estimate fewer than 10 organic tobacco producers in Kentucky at time of publication.

Azoxystrobin is the only systemic, synthetic fungicide labeled for tobacco production in the U.S. for the control of foliar, fungal diseases. It is among the oldest fungicides in the outer quinol oxidation site inhibitor (QoI) fungicide class and has been labeled for commercial agricultural use since 1994 (Fernández-Ortuño et al. 2010). Biological control products such as those with Bacillus spp. active ingredients and synthetic protectant fungicides, with copper or mancozeb as active ingredients, are labeled for tobacco; however, these are utilized by a minority of growers due to efficacy concerns or in avoidance of undesirable residues in cured leaves. Thus, some growers apply up to four sequential azoxystrobin applications in a given tobacco season (personal communication). Numerous aspects of the FLS pathosystem align with high risk factors associated with fungicide resistance by the Fungicide Resistance Action Committee (FRAC) (Brent and Holloman 2007; NAFRAC 2019), including azoxystrobin's single-site mode of action, multiple applications per year, exclusive usage without integration of other modes of action, frequent application for curative rather than preventative purposes, geographically large usage areas, and the potential for sublethal dosages applied to tobacco. As of 2019, the maximum rate of azoxystrobin products labeled for tobacco was 0.877 liter/ha; however, replicated trials indicated that an azoxystrobin rate of 0.585 liter/ha managed target spot (caused by Thanatephorus cucumeris) equally well (Seebold 2008; Seebold and Henderson 2010; Seebold and Palmer 2007; Seebold and Sizemore 2011). Target spot has historically been a more yield-limiting fungal leaf spot in tobacco compared with FLS. Azoxystrobin has been labeled for tobacco disease management in Kentucky since at least 2005, in which the only rate indicated was 0.585 liter/ha (FIFRA 2005).

Resistance to QoI fungicides has been documented in other agriculturally relevant Cercospora spp., including C. sojina (Standish et al. 2015; Zhang et al. 2012), C. kikuchii (Price et al. 2015), and C. beticola (Birla et al. 2012; Bolton et al. 2012; Vaghefi et al. 2016). In each of these pathosystems, the G143A mutation within the cytochrome $b$ gene has been reported at higher prevalence than 
the F129L mutation. Isolates with the G143A mutation, which results in an amino acid substitution from glycine to alanine, have effective concentration to inhibit $50 \%$ germination $\left(\mathrm{EC}_{50}\right)$ values ranging from 5- to 1,000-fold higher than the $\mathrm{EC}_{50}$ values of baseline isolates (Bradley and Pedersen 2011; Vaghefi et al. 2016; Zhang et al. 2012). Isolates with the F129L mutation, which results in an amino acid substitution from phenylalanine to leucine, have $\mathrm{EC}_{50}$ values 10- to 140-fold higher than baseline isolates when evaluated with conidial germination assays in Pyricularia grisea, Alternaria solani, and C. beticola (Kim et al. 2003; Pasche et al. 2005; Vaghefi et al. 2016). References from other Cercospora pathosystems detail baseline $\mathrm{EC}_{50}$ values in nonexposed isolates for azoxystrobin ranging from 0.002 to $0.16 \mu \mathrm{g} / \mathrm{ml}$ (Bradley and Pedersen 2011; Price et al. 2015; Vaghefi et al. 2016; Zhang et al. 2012).

Neither the alternative oxidase respiration pathway nor a comparison of QoI fungicide sensitivity assays has been previously completed in C. nicotianae. Several agriculturally relevant Cercospora spp. have been found to utilize the alternative oxidase pathway (Bradley and Pedersen 2011; Price et al. 2015; Vaghefi et al. 2016; Zhang et al. 2012), which has been described as a respiratory "rescue mechanism" deployed by some fungi in in vitro evaluations of QoI fungicide sensitivity (Fernández-Ortuño et al. 2010; Zhang et al. 2012). Amending fungicide sensitivity culture media with salicylhydroxamic acid (SHAM) has been used to eliminate potential spore germination via the alternative respiration pathway (Olaya and Koller 1999). For many studies evaluating sensitivity to QoIs, a conidial germination assay has been utilized (Bradley and Pedersen 2011; Secor et al. 2010; Vaghefi et al. 2016; Zhang et al. 2012), though mycelial growth assays were also used (Price et al. 2015). QoI fungicides inhibit adenosine-triphosphate production by binding the quinol oxidation site of cytochrome $b c_{1}$ (Fernández-Ortuño et al. 2010), which has been suggested to have greater influence over conidial germination than mycelial growth (Vaghefi et al. 2016).

Because azoxystrobin is the only currently labeled, systemic fungicide option for FLS management in tobacco, documentation of the sensitivity of $C$. nicotianae isolates to this active ingredient and correlations with production systems are critical to elucidating resistance prevention and mitigation strategies. Therefore, specific objectives of the study were to (i) establish azoxystrobin sensitivity distributions from $C$. nicotianae isolates collected from Kentucky tobacco in 2016 and 2017, (ii) identify point mutations conferring resistance to azoxystrobin in a priori phenotyped $C$. nicotianae isolates, and (iii) compare azoxystrobin sensitivity patterns in isolates from greenhouse transplants and field-grown tobacco approaching harvest, as well as organic and conventional management regimes.

\section{Materials and Methods}

Sampling. FLS samples were acquired from seven tobacco farms in each of 2016 and 2017, resulting in 47 and 53 C. nicotianae isolates, respectively, in each sample year. Information on collection year, Kentucky county of origin, age of sampled plant material, management system, and tobacco type is provided in Table 1. Fieldgrown tobacco was sampled within 1 month of harvest and had been treated with azoxystrobin in some cases. When multiple samples were collected per field, plants were located no less than $10 \mathrm{~m}$ apart. Samples collected in 2016 were from farms in which the grower suspected a loss of control (except for samples from the organic farm). C. nicotianae isolates collected prior to 2005 (marking azoxystrobin's first usage in tobacco) are not known to exist. Samples from 2017 were collected at the first suspected incidence of FLS in greenhouse transplants (Dixon et al. 2018), submitted to the University of Kentucky Plant Disease Diagnostic Laboratories, or collected during other visits to grower fields by extension agents or specialists.

Single-sporing and isolate storage. Single-conidium isolates were generated from lesions on tobacco leaves. In most cases, a single conidium was removed from a sporulating lesion with a scalpel blade as visualized under a dissecting microscope. Where sporulation was not present on the sample surface, a mycelial culture was initiated on one-quarter acidified potato dextrose agar (1/4 aPDA; Difco, Becton Dickinson and Company, MD, U.S.A.); then, the culture was transferred to clarified V8 juice agar to induce sporulation. Briefly, V8 juice agar was made by stirring commercial V8 juice with a final concentration of $1.5 \% \mathrm{CaCO}_{3}$ for $30 \mathrm{~min}$, then centrifuging the solution for $10 \mathrm{~min}$ at 3,000 rpm. Clarified V8 suspension was combined

Table 1. Cercospora nicotianae isolates collected from Kentucky tobacco in 2016 and 2017 and included in azoxystrobin sensitivity assays

\begin{tabular}{|c|c|c|c|c|c|c|}
\hline Isolate range $^{u}$ & Number of isolates & Year collected & County of origin & Host age & Management & Tobacco type \\
\hline $16 \mathrm{Cn} 001-010$ & 9 & 2016 & Green & Mature & Conventional & Burley \\
\hline $16 \mathrm{Cn} 011-020$ & 9 & $2016^{\mathrm{v}}$ & Metcalfe & Mature & Conventional & Burley \\
\hline $16 \mathrm{Cn} 022-029$ & 8 & 2016 & Barren & Mature & Conventional & Burley \\
\hline $16 \mathrm{Cn} 031-040$ & 9 & 2016 & Metcalfe & Mature & Conventional & Burley \\
\hline $16 \mathrm{Cn} 041-050$ & 10 & 2016 & Barren & Mature & Conventional & Burley \\
\hline $16 \mathrm{Cn} 056-058$ & 2 & 2016 & Scott & Mature & Organic & Burley \\
\hline $17 \mathrm{Cn} 001-006$ & 6 & $2017^{w}$ & Allen & Transplant & Conventional & Burley \\
\hline $17 \mathrm{Cn} 007-010$ & 4 & $2017^{\mathrm{w}, \mathrm{x}}$ & Allen & Transplant & Conventional & Burley \\
\hline $17 \mathrm{Cn} 011$ & 1 & 2017 & Barren & Transplant & Conventional & Burley \\
\hline 17Cn012-016 & 4 & 2017 & Barren & Transplant & Conventional & Burley \\
\hline 17Cn017-021 & 5 & $2017^{y}$ & Metcalfe & Transplant & Conventional & Burley \\
\hline 17JJ501-JJ614e & 4 & $2017^{\mathrm{v}, \mathrm{y}}$ & Metcalfe & Mature & Conventional & Burley \\
\hline 17D1-D7 & 7 & 2017 & Christian & Mature & Organic & Burley \\
\hline 17H1a-H2e & 4 & $2017^{z}$ & Daviess & Mature & Conventional & Dark \\
\hline 17H1405a & 1 & 2017 & Metcalfe & Mature & Conventional & Burley \\
\hline 17L101-407 & 3 & 2017 & Todd & Mature & Conventional & Dark \\
\hline 17P751a-d & 3 & $2017^{z}$ & Daviess & Mature & Conventional & Burley \\
\hline $17 \mathrm{P} 752 \mathrm{a}-\mathrm{c}$ & 2 & $2017^{z}$ & Daviess & Mature & Conventional & Burley \\
\hline 17P753b-d & 3 & $2017^{z}$ & Daviess & Mature & Conventional & Burley \\
\hline $17 \mathrm{P} 754 \mathrm{~b}-\mathrm{c}$ & 2 & $2017^{z}$ & Daviess & Mature & Conventional & Burley \\
\hline $17 \mathrm{P} 755 \mathrm{a}-\mathrm{d}$ & 3 & $2017^{z}$ & Daviess & Mature & Conventional & Dark \\
\hline $17 \mathrm{P} 846$ & 1 & $2017^{x}$ & Allen & Mature & Conventional & Burley \\
\hline
\end{tabular}

u Isolate ranges reported in groups by field or greenhouse sampled.

v Samples originated from mature tobacco from the same production field visited in 2016 and 2017.

${ }^{w}$ Samples were collected from the same general greenhouse area managed by the same grower but represented two different transplant lots started on 1 March (17Cn001 set) and 10 March (17Cn007 set).

x Samples originated from identical transplant lots gathered in April and August for transplant and mature tobacco, respectively.

y Samples originated from identical transplant lots gathered in April and July for transplant and mature tobacco, respectively.

z Samples collected from different fields managed by the same grower on the same farm. 
with deionized (DI) water to a final concentration of $20 \%$. After adding agar at $15 \mathrm{~g} /$ liter, the media was autoclaved and poured into Petri plates while still molten. A plug from the sporulating culture was transferred to $10 \mathrm{ml}$ of sterile DI water and agitated with a vortex, and $0.1 \mathrm{ml}$ of aliquot was spread on 1/4 aPDA. After $24 \mathrm{~h}$, a single germinating spore was transferred to V8 juice agar and grown as a single conidium isolate. Each isolate was grown individually on V8 juice culture and placed under $12 \mathrm{~h}$ of black to blue light (370 to $400 \mathrm{~nm}$ wavelength) to induce sporulation; then, conidia were harvested and frozen in $15 \%$ glycerol at $-80^{\circ} \mathrm{C}$ until further processing. Small aliquots of frozen conidial suspensions were utilized to revive isolates as needed.

Evaluation of the alternative oxidase pathway in $C$. nicotianae. To determine the presence of the alternative oxidase pathway in $C$. nicotianae (Fernández-Ortuño et al. 2010; Zhang et al. 2012), 12 isolates representative of sample years and locations were chosen to determine the effect of SHAM on conidial germination of $C$. nicotianae. SHAM (final concentration $0,60,70$, or $100 \mathrm{ppm}$; dissolved in methanol) was included or not in the presence of six concentrations of technical-grade azoxystrobin $(0,0.001,0.01,0.1,1$, and $10 \mu \mathrm{g} / \mathrm{ml})$ (Syngenta Crop Protection, Greensboro, NC, U.S.A.). This range of SHAM concentrations was selected because, in QoI sensitivity evaluations of A. solani (Rosenzweig et al. 2008), C. zeae-maydis (Bradley and Pedersen 2011), C. sojina (Zhang et al. 2012), C. beticola (Vaghefi et al. 2016), and P. grisea (Vincelli and Dixon 2002), SHAM concentrations used were 100,60,100,60, and 100 ppm, respectively. Azoxystrobin was dissolved in acetone and all media contained a final concentration of $1 \%(\mathrm{vol} / \mathrm{vol})$ acetone. Conidial suspension methods approximated Zhang et al. (2012), with slight modifications. Conidial suspensions of each isolate were made by removing 8 to 107 -mm plugs from a 7- to 10-day-old, actively sporulating culture. Plugs were agitated with a vortex for approximately $30 \mathrm{~s}$ in $6 \mathrm{ml}$ of sterile DI water. The suspension was filtered through two layers of cheesecloth; then, $75 \mu \mathrm{l}$ was spread on each media plate. Three replicate plates of each SHAM-azoxystrobin combination were established for each isolate and stored in the dark at ambient temperature for 20 to $28 \mathrm{~h}$. In all, 100 conidia were evaluated for 2016 isolates and 50 conidia were evaluated for 2017 isolates. A conidium was considered germinated if the germ tube was at least half the length of the spore. At each azoxystrobin concentration, the number of germinated conidia was determined as a percentage of the germinated conidia in the nonamended medium, completed in three replicate plates (Vaghefi et al. 2016; Zhang et al. 2012) for each $C$. nicotianae isolate at each SHAM concentration. Germination percentages and corresponding fungicide concentrations were utilized in PROC PROBIT in Statistical Analysis Software (SAS; v. 9.4; SAS Institute Inc., Cary, NC, U.S.A.) (Pfeufer and Ngugi 2012; Vaghefi et al. 2016) to calculate the specific azoxystrobin concentration expected to inhibit $50 \%$ of conidial germination. PROC PROBIT was used to construct a normal regression model for each C. nicotianae isolate, in which the response (percent germinated conidia compared with the untreated control) was modeled against discrete $\log _{10}$ concentrations (doses) of azoxystrobin. The azoxystrobin concentration at which $50 \%$ inhibition was modeled indicated the $\mathrm{EC}_{50}$ value for each isolate (Pfeufer and Ngugi 2012). Experimental replicates were separated for the SHAM and sensitivity assay comparisons in order to generate three separate $\mathrm{EC}_{50}$ values for each isolate tested; however, replicates were combined in the same analysis for each isolate represented in the $\mathrm{EC}_{50}$ distributions by year.

Fungicide sensitivity assays in $C$. nicotianae. Conidial germination assays were similar to those described by Secor et al. (2010) and Zhang et al. (2012), with the following modifications. C. nicotianae isolates were grown from frozen culture for 7 to 10 days under black to blue light (wavelength 370 to $400 \mathrm{~nm}$ ) to induce sporulation. Conidia were dislodged from cultures, suspended in sterile DI water, and spread plated on amended media. Three replicate plates per isolate on each azoxystrobin concentration were prepared. Conidial germination was determined for 100 (2016 isolates) or 50 (2017 isolates) conidia per plate under a compound microscope at $\times 100$ magnification after 20 to $28 \mathrm{~h}$ of incubation. $\mathrm{EC}_{50}$ values were calculated using the conidial germination assay described above for 47 and 53 isolates from 2016 and 2017, respectively.

To compare broadly utilized fungicide sensitivity assays, $14 C$. nicotianae isolates were tested on PDA amended with azoxystrobin at $0,0.001,0.01,0.1,1.0$, and $10 \mu \mathrm{g} / \mathrm{ml}$ in order to determine the $\mathrm{EC}_{50}$ for mycelial growth or conidial germination. These isolates were chosen to be representative of both sample years and unique sample sites, and based on results from initial azoxystrobin sensitivity evaluations completed using the conidial germination assay. For these comparisons, the conidial germination assay was repeated on identical media used for the mycelial growth assay. In both assays, PDA was amended with azoxystrobin to the final concentrations listed after media were sterilized and warm to touch but still molten. Based on results from the previously described experiments, both mycelial growth and conidial germination media were amended to a final concentration of SHAM at $70 \mathrm{ppm}$.

Mycelial growth evaluation assays were conducted using the methods described by Pfeufer and Ngugi (2012) and Smith et al. (1991). Mycelial plugs were removed from the leading edge of isolate culture plates using a number 3 cork borer (approximately $5 \mathrm{~mm}$ in diameter), and plugs were placed in plates with the same size area removed from the center. Each isolate-concentration combination was tested in three replicate plates. Using a handheld digital caliper, mycelial growth of the colony was measured on two perpendicular diameters at $3,5,7,10$, and 14 days postplug transfer. $\mathrm{EC}_{50}$ values were calculated using PROC PROBIT as described above, with the response being 14-day colony diameter as a percentage of the same isolate growth on nonamended media (Pfeufer and Ngugi 2012).

Amplification and sequencing of partial cytochrome b gene of selected $C$. nicotianae isolates. Twenty-two isolates were selected for PCR and subsequent sequencing based on sample year, sample location, and a priori phenotyped azoxystrobin $\mathrm{EC}_{50}$ value from conidial germination assays, as determined above. After the initial identification of the F129L mutation in isolate $16 \mathrm{Cn} 004$, the remaining seven isolates from that sample site were amplified and sequenced. Isolates were grown on clarified V8 juice medium for 8 to 10 days; then, mycelia and conidia were harvested, lyophilized, and extracted using the cetyltrimethylammonium bromide method of $\mathrm{Li}$ et al. (2008), with one modification. The single modification was an initial extraction with an equal volume of phenol/chloroform/isoamylalcohol (50:49:1) after the first heating step. DNA was quantified using the Qubit fluorometer (Invitrogen Technologies, Carlsbad, CA, U.S.A.) and stored at $4^{\circ} \mathrm{C}$ until further use.

Amplification of partial cytochrome $b$ was accomplished using the mut4 primer set, which flanks the region of $C$. sojina cytochrome $b$ encompassing the F129L, G137R, and G143A mutation sites (Zeng et al. 2015). PCR cycling conditions were as described by Zeng et al. (2015); however, only $15 \mathrm{ng}$ of template was used per reaction. Amplicons were approximately 380 bp when visualized on a $1 \times$ Tris-acetate-EDTA gel; then, PCR products were cleaned using ExoSAP-IT (Affymetrix, Inc., Cleveland, OH, U.S.A.). PCR products were Sanger sequenced by Eurofins Genomics (Eurofins Inc., Louisville, KY, U.S.A.). Forward and reverse sequences were trimmed of low-quality reads and aligned with ApE (A Plasmid Editor, v2.0.55; https://jorgensen.biology.utah.edu/wayned/ape/) to acquire consensus sequences. The consensus sequences for each isolate were then aligned with Clustal Omega (https://www.ebi.ac.uk/Tools/ msa/clustalo/) utilizing default settings. All consensus sequences exhibited homology to fungal cytochrome $b$ genes in GenBank, including closely related species $C$. beticola and C. kikuchii. Sequences of selected isolates are available in GenBank (Table 2).

Data analysis. Distributions of $\mathrm{EC}_{50}$ values for $C$. nicotianae isolates for each sampling year were constructed by subtracting the largest $\mathrm{EC}_{50}$ (2.795) from the smallest $\mathrm{EC}_{50}(0.0187)$, dividing by 30 (each value referred to as a bin), and using the range around each bin to collapse values into bars. Normality of each year's distribution was assessed using the normaltest option in PROC UNIVARIATE in SAS. Azoxystrobin $\mathrm{EC}_{50}$ values in the presence of SHAM at 0,60 , 70 , and $100 \mathrm{ppm}$ were compared for selected isolates using PROC 
GLM in SAS. If the experiment-wise $F$ test indicated an experimentwise difference among the treatments, means were separated using Fisher's least significant difference. After applying a $\log _{10}$ transformation, the Wilcoxon rank-sum test was conducted using PROC NPAR1WAY on $\mathrm{EC}_{50}$ values grouped by sampling location (transplant or field-grown) or management system (conventional or organic) and evaluating isolates from burley tobacco only. Transplant isolates were excluded from the management system analysis, and organic isolates were excluded from the sample location analysis.

For additional comparisons on the effect of sample location and production system on $C$. nicotianae azoxystrobin sensitivity, isolates were grouped by their conidial germination assay $\mathrm{EC}_{50}$ values, utilizing ranges indicative of sensitive, F129L, or G143A partial $c y$ tochrome $b$ sequence results. Isolates with $\mathrm{EC}_{50}$ values for azoxystrobin at less than $0.038 \mu \mathrm{g} / \mathrm{ml}$ were considered sensitive for these analyses, 0.177 to $0.535 \mu \mathrm{g} / \mathrm{ml}$ were moderately resistant, and $>1.150 \mu \mathrm{g} / \mathrm{ml}$ were highly resistant, corresponding to sensitivity patterns of assumed-sensitive isolates, those with an F129L mutation, or those with the G143A mutation, respectively. A two-by-three $\chi^{2}$ comparison between greenhouse transplant and field-grown sample isolates from burley tobacco was completed using PROC NPAR1WAY. Similarly, a two-by-two analysis was completed between isolates from samples of organic and conventionally managed burley tobacco utilizing only the sensitive and moderately resistant isolates, due to small overall organic sample numbers. For all statistical tests, significant results were indicated by $\alpha=0.05$.

\section{Results}

Comparisons of fungicide sensitivity assay methods and determination of an alternative oxidase pathway in selected isolates. The azoxystrobin $\mathrm{EC}_{50}$ values for 9 of $14 C$. nicotianae isolates differed depending on the fungicide sensitivity assay used $(P<$ 0.05; Table 2). The conidial germination assay clustered isolate $\mathrm{EC}_{50}$ values into single orders of magnitude, whereas the mycelial growth assay encompassed broader ranges of sensitivity. For example, $\mathrm{EC}_{50}$ values from highly resistant isolates ranged from 1.212 to $3.021 \mu \mathrm{g} / \mathrm{ml}$ utilizing the conidial germination assay but the same isolates had $\mathrm{EC}_{50}$ values for azoxystrobin at $>10 \mu \mathrm{g} / \mathrm{ml}$ in the mycelial growth assay. Four isolates (16Cn004, 16Cn043, $17 \mathrm{JJ} 614 \mathrm{c}$, and $16 \mathrm{Cn} 008$ ) had significantly lower $\mathrm{EC}_{50}$ values when the conidial germination assay was conducted in the presence of SHAM at $70 \mathrm{ppm}(P<0.05$; Table 2$)$. In one of two experiments, there was no significant difference in azoxystrobin sensitivity between SHAM at 0 and $60 \mathrm{ppm}$ for isolate 16Cn008 (Table 2). Based on these data, all remaining $\mathrm{EC}_{50}$ values were determined in media amended with SHAM at $70 \mathrm{ppm}$.

C. nicotianae isolate $\mathrm{EC}_{50}$ distributions from 2016 and 2017. In $2016, \mathrm{EC}_{50}$ values were determined for $47 \mathrm{C}$. nicotianae isolates originating from six tobacco fields located in four counties in Kentucky. The majority of isolates $(n=40)$ had $\mathrm{EC}_{50}$ values for azoxystrobin in the range of 0.178 to $0.360 \mu \mathrm{g} / \mathrm{ml}$, with the overall isolate $\mathrm{EC}_{50}$ range spanning 0.0274 to $2.795 \mu \mathrm{g} / \mathrm{ml}$. The 2016 distribution was nonnormal (Shapiro-Wilk test, $P$ value $\leq 0.01$; data not shown), with isolate $\mathrm{EC}_{50}$ values grouping roughly into three orders of magnitude for azoxystrobin at around $0.03,0.3$, and $2.0 \mu \mathrm{g} / \mathrm{ml}$. Isolates with azoxystrobin $\mathrm{EC}_{50}$ values $>1.5 \mu \mathrm{g} / \mathrm{ml}$ originated from two different farms (Fig. 1A).

In $2017, \mathrm{EC}_{50}$ values were determined for 53 C. nicotianae isolates originating from nine farms located in six counties in Kentucky (Fig. 1B). A more thorough sampling of an organically managed field (without exposure to azoxystrobin for a minimum of 3 years) and isolates from dark tobacco were included in 2017, which together accounted for 8 of the 11 isolates with $\mathrm{EC}_{50}<0.085 \mu \mathrm{g} / \mathrm{ml}$. As with the 2016 dataset, the $2017 \mathrm{EC}_{50}$ values were nonnormally distributed (Shapiro-Wilk test, $P$ value $\leq 0.01$; data not shown). In 2017,31 of 53 isolates had $\mathrm{EC}_{50}$ values in the range of 0.178 to $0.360 \mu \mathrm{g} / \mathrm{ml}$, and $\mathrm{EC}_{50}$ distributions for azoxystrobin grouped around $0.03,0.3$, and $2.0 \mu \mathrm{g} / \mathrm{ml}$. Six isolates with $\mathrm{EC}_{50}>1.150 \mu \mathrm{g} / \mathrm{ml}$ were identified, which originated from four different farms in three counties (Fig. 1B). Mean and median $C$. nicotianae isolate $\mathrm{EC}_{50}$ values were 0.358 and $0.270 \mu \mathrm{g} / \mathrm{ml}$, respectively, for 2016 and 0.451 and $0.271 \mu \mathrm{g} / \mathrm{ml}$, respectively, for 2017 (Fig. 1A and B).

Effect of location and production system on $C$. nicotianae azoxystrobin sensitivity. C. nicotianae $\mathrm{EC}_{50}$ values grouped by plant sample location were not significantly different between isolates from transplant and field-grown burley tobacco samples when

Table 2. Effective azoxystrobin concentration to inhibit $50 \%$ of either conidial germination or mycelial growth $\left(\mathrm{EC}_{50}\right)$ and in the presence of salicylhydroxamic acid (SHAM) at 0, 60, 70, or $100 \mathrm{ppm}$ for selected Cercospora nicotianae isolates

\begin{tabular}{|c|c|c|c|c|c|c|c|c|}
\hline \multirow[b]{2}{*}{ Isolate } & \multicolumn{3}{|c|}{ Sensitivity assay $\mathbf{E C}_{50}$ comparisons } & \multicolumn{4}{|c|}{ Azoxystrobin $\mathbf{E C}_{50}$ values at various SHAM concentrations $\mathbf{s}^{\mathbf{t}}$} & \multirow[b]{2}{*}{ Accession $^{v}$} \\
\hline & Germ & Growth & $P$ value ${ }^{u}$ & $\mathbf{0} \mathbf{p p m}$ & $60 \mathrm{ppm}$ & 70 ppm & $100 \mathrm{ppm}$ & \\
\hline $16 \mathrm{Cn} 058$ & 0.030 & 0.084 & 0.008 & 0.043 & 0.043 & 0.042 & 0.036 & MK369760 \\
\hline $16 \mathrm{Cn} 056$ & 0.036 & 0.061 & $0.340^{\mathrm{w}}$ & $\ldots$ & $\ldots$ & $\ldots$ & $\ldots$ & MK369759 \\
\hline 17D1 & 0.038 & 0.777 & $0.018^{\mathrm{w}}$ & 0.030 & 0.031 & 0.034 & 0.036 & MK369764 \\
\hline $16 \mathrm{Cn} 026$ & 0.245 & 3.324 & $0.011^{\mathrm{w}}$ & 0.653 & 0.470 & 0.710 & 0.337 & MK369756 \\
\hline $16 \mathrm{Cn} 004$ & 0.283 & 4.030 & 0.001 & $3.933 \mathrm{a}^{\mathrm{x}, \mathrm{y}}$ & $0.648 \mathrm{~b}$ & $0.477 \mathrm{~b}$ & $0.349 \mathrm{~b}$ & MK369750 \\
\hline $16 \mathrm{Cn} 009$ & 0.292 & 2.431 & $0.017^{\mathrm{w}}$ & 0.217 & 0.187 & 0.169 & 0.191 & MK369754 \\
\hline 17JJ501e & 0.313 & 2.243 & $0.028^{\mathrm{w}}$ & $\ldots$ & $\ldots$ & $\ldots$ & $\ldots$ & MK369765 \\
\hline 17P751a & 0.332 & 7.237 & $0.036^{\mathrm{w}}$ & 0.394 & 0.456 & 0.445 & 0.403 & MK369767 \\
\hline $16 \mathrm{Cn} 043$ & 0.340 & 2.431 & $0.019^{\mathrm{w}}$ & $0.204 \mathrm{a}$ & $0.124 \mathrm{~b}$ & $0.137 \mathrm{~b}$ & $0.125 \mathrm{~b}$ & MK369758 \\
\hline 17JJ614c & 1.212 & 36.522 & $0.004^{w}$ & $7.479 \mathrm{a}$ & $3.976 \mathrm{~b}$ & $4.118 \mathrm{~b}$ & $3.470 \mathrm{~b}$ & MK369766 \\
\hline $16 \mathrm{Cn} 035$ & 1.891 & 118.700 & $0.035^{\mathrm{w}}$ & 6.350 & 4.102 & 5.700 & 5.564 & MK369757 \\
\hline $17 \mathrm{Cn} 018$ & 2.531 & 39.945 & $0.096^{\mathrm{w}}$ & 3.815 & 2.692 & 3.390 & 2.990 & MK369762 \\
\hline $16 \mathrm{Cn} 008$ & 2.879 & 53.748 & $0.061^{\mathrm{w}}$ & $3.177 \mathrm{a}^{\mathrm{z}}$ & $2.957 \mathrm{ab}$ & $2.700 \mathrm{~b}$ & $2.590 \mathrm{~b}$ & MK369753 \\
\hline $17 \mathrm{Cn} 006$ & 3.021 & $1,137.800$ & $0.202^{\mathrm{w}}$ & 4.080 & 2.107 & 2.797 & 2.046 & MK369761 \\
\hline
\end{tabular}

$\mathrm{s}$ Results from conidial germination (Germ) and mycelial growth (Growth) assays were compared using a $t$ test; means are reported. Media were amended with SHAM at $70 \mathrm{ppm}$.

${ }^{t} \mathrm{EC}_{50}$ values using different SHAM concentrations were compared using the conidial germination assay and a one-way analysis of variance; mean $\mathrm{EC}_{50}$ values are reported.

u Azoxystrobin $\mathrm{EC}_{50}$ values of each isolate compared using a $t$ test.

$\checkmark$ GenBank accessions. Partial cytochrome b sequence amplified using the mut4 primer set (Zhang et al. 2012).

w A Satterthwaite correction to the $P$ value is reported due to results from the Folded $F$ test, which indicated unequal variances about the treatment mean

${ }^{x}$ Means for each isolate by SHAM concentration were separated using Fisher's protected least significant difference; statistically significant differences $(P \leq$ $0.05)$ are indicated across the row.

y Three replicate experiments were completed with similar results; means from one representative experiment shown.

${ }^{\mathrm{z}}$ In one experiment, all SHAM concentrations were significantly different from the 0-ppm SHAM treatment; means shown are from a separate experiment in which the 60-ppm SHAM treatment was not significantly different from the 0-ppm SHAM treatment. 
Wilcoxon signed-rank tests were utilized $(Z=-0.271, P=0.788$; Table 3). Using the same signed-rank test, isolates from organic production systems had lower median $\mathrm{EC}_{50}$ values than isolates from samples from conventional production systems $(Z=-3.804, P<$ 0.001; Table 3).

In $\chi^{2}$ analyses, in which isolates were grouped according to threshold $\mathrm{EC}_{50}$ values indicated by partial cytochrome $b$ sequence data (Fig.
2), significant differences in isolate frequencies were found according to the sampling location and production system. Proportionally more highly resistant $C$. nicotianae individuals were isolated from transplant samples as compared with field-grown tobacco $\left(\chi^{2}=8.283, P=0.019\right.$; Table 4). Proportionally more moderately resistant individuals were isolated from conventionally produced samples compared with organically produced samples $\left(\chi^{2}=55.770, P<0.001\right.$; Table 4$)$.
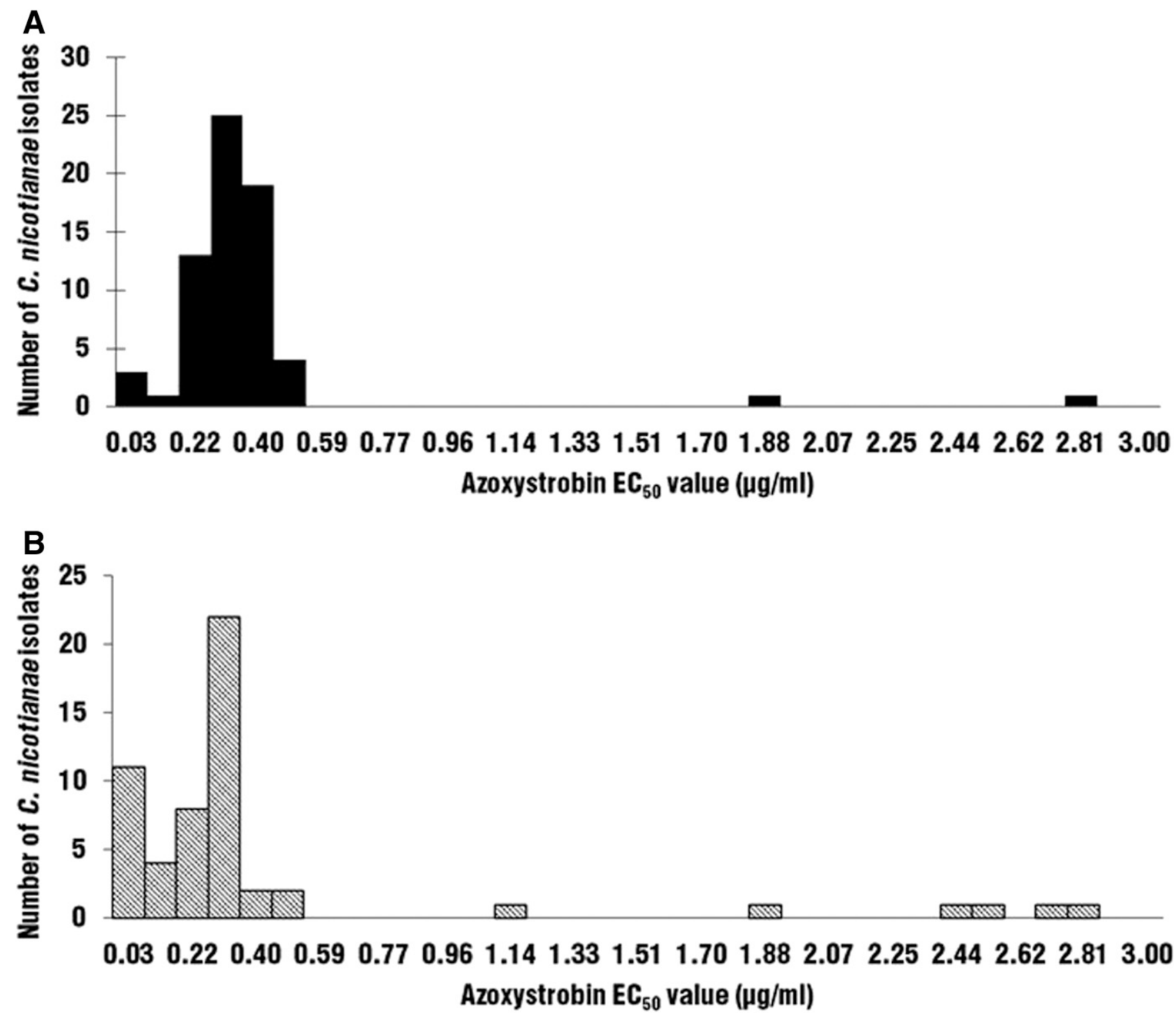

Fig. 1. Distributions of effective azoxystrobin concentration to inhibit $50 \%$ of conidial germination $\left(\mathrm{EC}_{50}\right)$ values of Cercospora nicotianae isolates from tobacco crops in Kentucky. C. nicotianae isolates were collected in A, 2016 and B, 2017. X-axes show every other bin value.

Table 3. Effect of sample location (transplant or field-grown) or production system (organic or conventional) on median Cercospora nicotianae azoxystrobin concentration to inhibit $50 \%$ of conidial germination $\left(\mathrm{EC}_{50}\right)$ values ${ }^{\mathrm{x}}$

\begin{tabular}{|c|c|c|c|c|c|}
\hline \multirow[b]{2}{*}{ Sample descriptor } & \multirow[b]{2}{*}{ Sample detail } & \multirow[b]{2}{*}{$\mathrm{EC}_{50}$ range } & \multicolumn{3}{|c|}{ Wilcoxon signed rank test } \\
\hline & & & Median $\mathbf{E C}_{50}$ & $Z$ value & Two-tailed $t P$ value \\
\hline \multirow[t]{2}{*}{$\overline{\text { Location }}$} & Transplants $(n=21)$ & $0.025-2.753$ & 0.272 & $\ldots$ & $\ldots$ \\
\hline & Field-grown $(n=65)^{\mathrm{y}}$ & $0.025-2.795$ & 0.280 & -0.271 & 0.788 \\
\hline \multirow[t]{2}{*}{ Production system } & Organic $(n=9)^{\mathrm{z}}$ & $0.019-0.579$ & 0.035 & $\ldots$ & $\ldots$ \\
\hline & Conventional $(n=65)$ & $0.025-2.795$ & 0.280 & -3.804 & $<0.001$ \\
\hline
\end{tabular}

$\mathrm{x}$ Data were log-transformed prior to statistical tests; nontransformed values are shown.

y Isolates from conventionally produced burley tobacco only.

${ }^{\mathrm{z}}$ Isolates from mature burley tobacco only. 
Partial cytochrome $b$ sequence comparisons of selected $C$. nicotianae isolates. Mutations demonstrated to confer resistance in other pathosystems were identified within $C$. nicotianae cytochrome $b$ sequences, which corresponded to order-of-magnitude azoxystrobin sensitivity groupings. Isolates with azoxystrobin $\mathrm{EC}_{50} \leq$ $0.038 \mu \mathrm{g} / \mathrm{ml}$ were the presumed wild type at codons 129,137 , and 143 and considered fully sensitive. C. nicotianae samples isolated prior to the use of azoxystrobin on tobacco were not available, because this active ingredient has been labeled for the crop since at least 2005. Isolates with $\mathrm{EC}_{50}$ for azoxystrobin within the range 0.177 to $0.535 \mu \mathrm{g} / \mathrm{ml}$ carried a single-nucleotide polymorphism (SNP) conferring the F129L mutation, and were considered moderately resistant to azoxystrobin. Sequences of 11 of 17 moderately resistant isolates indicated a C to A SNP at this locus (Fig. 2). However, six isolates carried a $\mathrm{C}$ to $\mathrm{G} \mathrm{SNP}$ in the same location $(16 \mathrm{Cn} 003$, 16Cn004, 16Cn007, 17P753b, 17D7, and 17H1d; Fig. 2). At the codon level, these SNPs confer a synonymous amino acid change from phenylalanine to leucine. C. nicotianae isolates with azoxystrobin $\mathrm{EC}_{50}>1.150 \mu \mathrm{g} / \mathrm{ml}$ carried a G to C SNP, which conferred the G143A mutation (Fig. 2). The G143A SNP results in an amino acid change from glycine to alanine, and these isolates were highly resistant to azoxystrobin. Both sample years were represented within the sensitive, moderately resistant, and highly resistant sequence groupings from four, eight, and seven unique sample sites, respectively (Table 1; Fig. 2). Sequences of selected isolates were deposited in GenBank, with accessions in Table 1.

\section{Discussion}

FLS now limits tobacco yield and quality in the United States, where previously it had been regarded as a minor disease with few to no economic implications. Azoxystrobin currently is the only systemic, synthetic fungicide labeled for U.S. tobacco production and, as such, it is heavily relied upon for FLS management. Loss of efficacy of this fungicide through the development of resistance has critical implications for U.S. tobacco growers.

$\mathrm{EC}_{50}$ values of C. nicotianae isolates from Kentucky in 2016 and 2017 indicated qualitative resistance around azoxystrobin concentrations of $0.03,0.3$, and $2.0 \mu \mathrm{g} / \mathrm{ml}$ (Fig. 1), which is the first documentation of fungicide resistance in this organism. The assumed sensitivity of wild-type $C$. nicotianae in Kentucky is azoxystrobin at $0.03 \mu \mathrm{g} / \mathrm{ml}$, which is comparable with baseline levels in other Cercospora spp. evaluated with this fungicide (Bradley and Pedersen 2011; Price et al. 2015; Vaghefi et al. 2016; Zhang et al. 2012). Order-of-magnitude shifts in sensitivity are characteristic of resistance to QoI fungicides in general (FRAC 2018) and have been documented for A. solani, C. kikuchii, C. beticola, and C. sojina (Pasche et al. 2005; Price et al. 2015; Rosenzweig et al. 2008; Vaghefi et al. 2016; Zhang et al. 2012). Distributions around discrete $\mathrm{EC}_{50}$ values presented here suggested three qualitative levels of azoxystrobin sensitivity, which were further evaluated through partial cytochrome $b$ sequence analysis to identify polymorphisms at mutation sites documented to confer resistance to azoxystrobin in C. sojina (Zeng et al. 2015).

Cytochrome $b$ sequence data indicated phenotype-specific SNPs. C. nicotianae isolates inhibited at low levels of azoxystrobin $(<0.038 \mu \mathrm{g} / \mathrm{ml})$ were determined to be sensitive and wild type at the F129L and G143A loci. Nucleotide sequences shown for the five sensitive $C$. nicotianae isolates in Figure 2 were identical to those of baseline C. beticola (GenBank accession number MF327260) and C. sojina (GenBank accession numbers KJ566928 to KJ566930) (Standish et al. 2015). Cytochrome $b$ sequence data generated for isolates with $\mathrm{EC}_{50}$ values ranging from 0.177 to $0.535 \mu \mathrm{g} / \mathrm{ml}$ carried a mutation at the F129L locus (Fig. 2). The more common point mutation found among these isolates, cytosine to adenine, was documented in QoI-resistant $P$. grisea (Kim et al. 2003) and C. beticola (Vaghefi et al. 2016), and was one of three SNPs conferring the F129L amino

Table 4. Effect of sample location (transplant or field-grown) or production system (organic or conventional) on Cercospora nicotianae isolates grouped by concentration to inhibit $50 \%$ conidial germination of a single-conidium $C$. nicotianae isolate $\left(\mathrm{EC}_{50}\right)$ values delineated based on partial cytochrome $b$ sequence

\begin{tabular}{lccccccc}
\hline & \multicolumn{5}{c}{ Number of isolates $^{\mathbf{y}}$} & & \\
\cline { 2 - 5 } Sample type & $\mathbf{S}$ & MR & HR & Total & $\boldsymbol{\chi}^{\mathbf{2}}$ Statistic & Two-tailed $\boldsymbol{P}$ value \\
\hline Transplants & 1 & 12 & 4 & 17 & $\ldots$ & $\ldots$ \\
Field & 0 & 58 & 4 & 62 & $\ldots$ & $\ldots$ \\
Totals & 1 & 70 & 8 & 79 & 8.283 & 0.019 \\
Organic & 6 & 1 & $0^{\mathrm{z}}$ & 7 & $\ldots$ & $\ldots$ \\
Conventional & 0 & 58 & $4^{\mathrm{z}}$ & 62 & $\ldots$ & $\ldots$ \\
Totals & 6 & 59 & $4^{\mathrm{z}}$ & 69 & $55.770^{\mathrm{z}}$ & $<0.001$ \\
\hline
\end{tabular}

${ }^{y}$ Sensitive $(\mathrm{S})$ isolates $\left(\mathrm{EC}_{50}<0.038 \mu \mathrm{g} / \mathrm{ml}\right)$, moderately resistant $(\mathrm{MR})$ isolates $\left(\mathrm{EC}_{50} 0.177\right.$ to $\left.0.535 \mu \mathrm{g} / \mathrm{ml}\right)$, and highly resistant $(\mathrm{HR})$ isolates $\left(\mathrm{EC}_{50}\right.$ $\geq 1.187 \mu \mathrm{g} / \mathrm{ml}$ ).

${ }^{\mathrm{z}}$ In production system comparisons, only $\mathrm{S}$ and MR isolate counts are compared, because sample numbers were too low to include the HR isolate grouping.

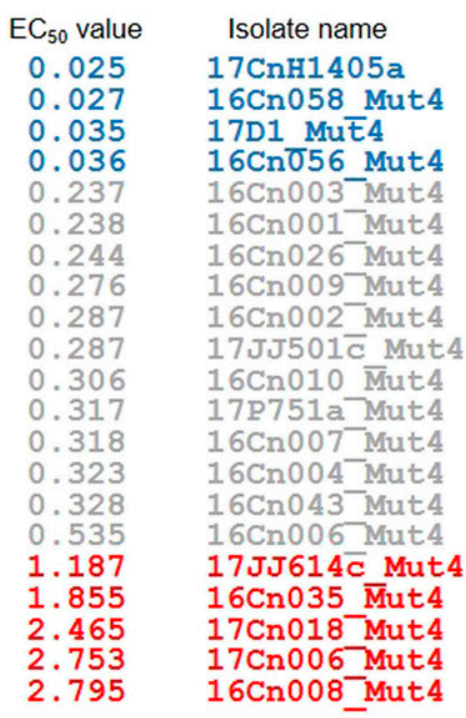

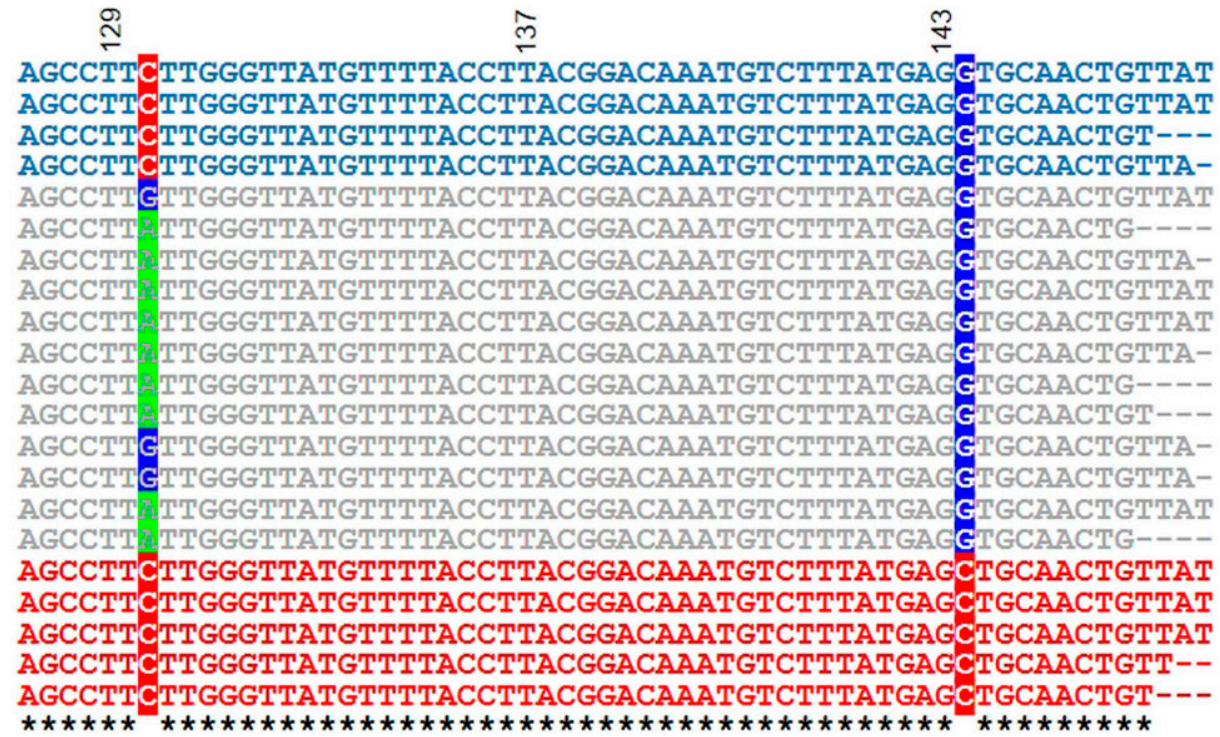

Fig. 2. Azoxystrobin effective concentration to inhibit $50 \%$ of conidial germination $\left(\mathrm{EC}_{50}\right)$ values and partial cytochrome $b$ sequence from Cercospora nicotianae isolates collected from tobacco with frogeye leaf spot symptoms in Kentucky in 2016 and 2017. Nucleotide polymorphisms in codons 129 and 143 are highlighted. 
acid substitution in Pyrenophora teres (Sierotzki et al. 2007) and A. solani (Rosenzweig et al. 2008). In the latter two pathogens, the less common C. nicotianae point mutation, cytosine to guanine, was also found (Rosenzweig et al. 2008; Sierotzki et al. 2007) although, similar to the data presented here, this SNP was less common in A. solani populations (Rosenzweig et al. 2008). The presence of multiple synonymous mutations conferring the F129L amino acid change has important implications for molecular identification of QoI resistance in C. nicotianae. From a grower perspective, commercially acceptable control of field populations composed of individuals with the F129L mutation has been reported by simply increasing the rate of fungicide applied (Fernández-Ortuño et al. 2010) but this has not yet been evaluated in the tobacco FLS pathosystem.

Unlike other Cercospora pathosystems where resistance to QoIs has been established (Price et al. 2015; Vaghefi et al. 2016; Zeng et al. 2015; Zhang et al. 2012), a minority (7 of 29) of sequenced C. nicotianae individuals carried the G143A mutation conferring high levels of resistance to azoxystrobin (Fig. 2). However, given limited sampling and the presence of high resistance phenotype isolates at seven different locations, individuals with this mutation should not be considered rare. Compared with the high frequency of $C$. nicotianae with moderate resistance (78 of 100 , occurring at all sample sites; Fig. 1A and B), less common occurrences of individuals with the G143A mutation may be related to both FLS epidemiology and grower standard practices in tobacco production. FLS typically begins on leaves in the lower tobacco canopy, and lesions are often only visible when plants reach $1 \mathrm{~m}$ or more. Though Extension recommendations indicate that the use of drop-nozzles is optimal (Johnson et al. 2019; Thiessen 2018), the authors estimate that fewer than $20 \%$ of growers actually utilize these sprayer modifications due to crop injury from the apparatuses as the sprayer moves through the field. Combined with the standard practice of applying submaximal dosages of azoxystrobin (Johnson et al. 2019; Thiessen 2018), the dose typically encountered by $C$. nicotianae in the field ranges from 359 to $599 \mu \mathrm{g} / \mathrm{ml}$ under conditions of perfect coverage, assuming typical volumes of 77 and 46 liter/ha, respectively. Lower than maximum fungicide rates combined with poor coverage would exert weaker selection pressure on pathogen populations compared with systems where excellent coverage and maximum azoxystrobin dosages were utilized. Studies are underway to evaluate mutation frequency dynamics in mixed populations where optimal fungicide coverage and application timing are achieved. Conversely, competitive fitness among $C$. nicotianae isolates with varying azoxystrobin sensitivities has not yet been documented, and it is possible that the G143A mutation may confer a fitness cost in $C$. nicotianae, even though reductions in fitness were not documented in $C$. sojina carrying the G143A mutation (Zhang and Bradley 2017).

Frequency comparisons based on production system or tobacco sample location provide further correlative evidence for the influences of fungicide coverage and competitive fitness in production environments. In this study, proportionally more $C$. nicotianae isolates from greenhouse-sampled, transplant-age tobacco had $\mathrm{EC}_{50}$ values indicating that the G143A mutation was present than $C$. nicotianae from field-grown, mature tobacco (Table 4). Azoxystrobin is labeled for one application per year in greenhouse tobacco transplant production for target spot management, caused by T. cucumeris (anamorph Rhizoctonia solani). C. nicotianae has only recently been shown to occur in greenhouse transplant systems (Dixon et al. 2018) and, in this confined space with very small plants, thorough fungicide coverage is more easily achieved compared with spray applications in the field. Consequently, $C$. nicotianae would be exposed to higher doses and greater selection pressure in the greenhouse environment, possibly resulting in the higher frequency of G143A mutants.

In comparisons of $C$. nicotianae isolate $\mathrm{EC}_{50}$ values from organically and conventionally produced tobacco, it is not surprising that mean and median values were significantly lower (Table 3 ) and isolate $\mathrm{EC}_{50}$ frequencies shifted toward sensitive (Table 4) from organically produced tobacco. Organic certification requires that no azoxystrobin be used in that field for 3 years prior to actual marketing of the crop as organic, resulting in little to no selection pressure for several seasons. Though sample numbers were small, one individual carrying the F129L mutation was identified from organic production systems (17D7; Fig. 2), and another is likely from the same population based on its calculated azoxystrobin $\mathrm{EC}_{50}$ value of $0.579 \mu \mathrm{g} / \mathrm{ml}$ (17D6). Two hypotheses that would follow from these occurrences are that (i) the F129L mutation does not impose a comparative fitness cost on C. nicotianae individuals or (ii) the F129L mutation is relatively common in wild populations of $C$. nicotianae. Comparatively, A. solani with the F129L mutation has been shown to have lower in vitro conidial germination rates but induced greater disease severity in vivo (Pasche and Gudmestad 2008). Similar experiments are being undertaken in the FLS pathosystem.

Other results presented here, for the first time in $C$. nicotianae, detail evidence for the presence of the alternative oxidase respiration pathway and a comparison of fungicide sensitivity assays. In several Cercospora spp., the alternative oxidase pathway has been documented as a "rescue mechanism" for pathogens to continue to respire during in vitro tests of QoI fungicide sensitivity (Bradley and Pedersen 2011; Fernández-Ortuño et al. 2010; Price et al. 2015; Vaghefi et al. 2016; Zhang et al. 2012). Data presented here indicate that some but not all $C$. nicotianae isolates were also capable of alternative respiration (Table 2). The choice of fungicide sensitivity assessment method can be influenced by pathogen trophic level, ease of in vitro sporulation induction, equipment and space availability, fungicide target site, and numerous other factors. In the FRAC publication on Monitoring Methods, A. solani, Mycosphaerella fijiensis, Phakopsora pachyrhizi, and Venturia inaequalis were all pathogens for which a conidial germination assay was recommended for QoI sensitivity testing (FRAC 2012). However, the recommended method for Sclerotinia sclerotiorum and $M$. graminicola QoI sensitivity determination was a mycelial growth assay, which was also used in recent $C$. kikuchii QoI sensitivity evaluations (Price et al. 2015). Comparisons of the two sensitivity assays for a selection of $C$. nicotianae isolates indicated statistically significant differences between calculated $\mathrm{EC}_{50}$ values for most tested individuals (Table 2). The conidial germination assay resulted in qualitative, order-of-magnitude groupings of isolate $\mathrm{EC}_{50}$ values, which is consistent with QoI fungicide sensitivity patterns recognized in other pathosystems (FRAC 2018; Sierotzki et al. 2007). More broadly, results presented here suggest that fungicide $\mathrm{EC}_{50}$ values determined using different evaluation assays may not be directly comparable, though this could be pathogen specific.

Contemporary increases in FLS severity may not solely be due to shifts in $C$. nicotianae sensitivity to azoxystrobin. For instance, rainfall data from one Kentucky county where FLS is particularly severe (Metcalfe), indicated that, in July and August 2015, 2016, and 2017, there were one, three, and one periods, respectively, of six or more consecutive days of rain (Kentucky Mesonet 2019). Compared with the earliest available rainfall records in Mesonet, in July and August 2010 to 2014, no 6-consecutive-day rainy period occurred (Kentucky Mesonet 2019). Environmental conditions notwithstanding, data presented here indicate that $C$. nicotianae populations from Kentucky tobacco are broadly shifted away from wild-type azoxystrobin sensitivity. With few, if any, azoxystrobin alternatives likely to be labeled for use in tobacco in the short term, practical extensions of this work include optimization of spray intervals and evaluation of variety susceptibility to FLS. Rapid-throughput resistance identification protocols are also needed so that commercial tobacco growers can make informed management decisions about fungicide applications. Though moderately resistant $C$. nicotianae plants were most common in this study, practical loss-of-control in tobacco fields has not yet been empirically attributed to the resistance status of pathogen populations, which will be a focus of future investigation. Furthermore, elucidation of strength of selection pressure will improve understanding of how $C$. nicotianae populations may change under different management regimes.

\section{Acknowledgments}

We thank S. Osborne and C. Hardy, University of Kentucky Cooperative Extension Agents, as well as 10 tobacco growers for site visit assistance; H. Li, research 
technologist, for submitting cytochrome $b$ sequence results to GenBank on behalf of B. Amsden and E. Pfeufer; B. Kennedy and J. Beale, University of Kentucky Plant Disease Diagnosticians, for assistance with sample maintenance; and an anonymous reviewer for her excellent presubmission feedback on the manuscript.

\section{Literature Cited}

Bickers, C. 2016a. How will the burley crop fare in the 2016 market? Tobacco Farmer Newsletter (blog). http://modtob.blogspot.com/2016/10/how-will-burleycrop-fare-in-2016-market_31.html

Bickers, C. 2016b. Which states still have tobacco in the field? Tobacco Farmer Newsletter (blog). http://modtob.blogspot.com/2016/10/which-states-still-havetobacco-in-field.html

Bickers, C. 2016c. Tobacco harvest nearing end with few bumper crops in sight. Tobacco Farmer Newsletter (blog). http://modtob.blogspot.com/2016/09/ virginia-dark-fire-cured-tobacco.html

Bickers, C. 2016d. Way too much rain for most tobacco. Tobacco Farmer Newsletter (blog). https://modtob.blogspot.com/2016/08/this-is-what-happenswhen-you-get-14.html

Bickers, C. 2017. Which way contracted acres? Flue-cured down, burley stable? Tobacco Farmer Newsletter (blog). http://modtob.blogspot.com/2017/02/ which-way-contract-acres-flue-cured.htm

Bickers, C. 2018. The rainy end of the 2018 season. Tobacco Farmer Newsletter (blog). http://modtob.blogspot.com/2018/10/the-wet-end-of-2018-season.html

Birla, K., Rivera-Varas, V., Secor, G. A., Khan, M. F., and Bolton, M. D. 2012. Characterization of cytochrome $b$ from European field isolates of Cercospora beticola with quinone outside inhibitor resistance. Eur. J. Plant Pathol. 134: 475-488.

Bolton, M., Rivera, V., and Secor, G. 2012. Identification of the G143A mutation associated with QoI resistance in Cercospora beticola field isolates from Michigan, United States. Pest Manage. Sci. 69:35-39.

Bradley, C. A., and Pedersen, D. K. 2011. Baseline sensitivity of Cercospora zeaemaydis to quinone outside inhibitor fungicides. Plant Dis. 95:189-194.

Brent, K. J., and Holloman, D. W. 2007. Fungicide Resistance: The Assessment of Risk. Fungicide Resistance Action Committee (Croplife International), Aimprint Publishing, Brussels, Belgium.

Dixon, E., Kennedy, B., Pearce, R., and Pfeufer, E. E. 2018. Occurrence of frogeye leaf spot, caused by Cercospora nicotianae, on greenhouse tobacco transplants in Kentucky. Plant Dis. 102:1036.

FIFRA. 2005. Quadris Flowable Fungicide, for control of certain diseases in tobacco. Federal Insecticide, Fungicide, and Rodenticide Act Section 18 Emergency Exemption. http://www.uky.edu/Ag/kpn/kyblue/product\%20labels/ Archive/Section\%2018\%20KY\%20Quadris\%20Tobacco\%202005.pdf

Fernández-Ortuño, D., Torés, J. A., de Vincente, A., and Pérez-garcía, A. 2010. The QoI fungicides, the rise and fall of a successful class of agricultural fungicides. Pages 203-220 in: Fungicides. O. Carisse, ed. InTech, Rijeka, Croatia.

Fowlkes, D. 2016. A Normal Season? Best Burley Issue 3, Fall 2016. Burley Stabilization Corporation newsletter. https://docs.wixstatic.com/ugd/cf4adf 16579cb11eb444f485887536c524cfdc.pdf

Fowlkes, D. 2017. Editor's Column: Price or Pounds? Best Burley Issue 7, Fall 2017. Burley Stabilization Corporation newsletter. https://docs.wixstatic.com/ ugd/cf4adf_58418d5c8c0d4fe1b7d1fe4d99b93e8f.pdf

FRAC. 2012. FRAC Monitoring Methods Status: January. Fungicide Resistance Action Committee. https://www.frac.info/docs/default-source/monitoring-methods/ method-list-status-jan-20128475CE308358.pdf?sfvrsn=fd7f469a_2

FRAC. 2018. QoI Working Group. Introduction and General Information. Fungicide Resistance Action Committee. https://www.frac.info/fracteams/working-groups/qol-fungicides/information

Johnson, C., Pfeufer, E., Hansen, Z., and Thiessen, L. 2019. Disease Management. 2019-2020 Burley and Dark Tobacco Production Guide, University of Kentucky Extension Publication ID-160. http://www2.ca.uky.edu/agcomm/ pubs/id/id160/id160.pdf

Kentucky Mesonet. 2019. The Commonwealth's Official Source for Weather and Climate Data. Monthly Data Summaries for Metcalfe County, KY, July and August 2010-2017. http://www.kymesonet.org/historical_data.php

Kim, Y.-S., Dixon, E. W., Vincelli, P., and Farman, M. L. 2003. Field resistance to strobilurin (QoI) fungicides in Pyricularia grisea caused by mutations in the mitochondrial cytochrome $b$ gene. Phytopathology 93:891-900.

Li, R., Mock, R., Huang, Q., Abad, J., Hartung, J., and Kindard, G. 2008. A reliable and inexpensive method of nucleic acid extraction for the PCR-based detection of diverse plant pathogens. J. Virol. Methods 154:48-55.

Lucas, G. B. 1975. Pages 305-308 in: Diseases of Tobacco, 3rd ed. Biological Consulting Associates, Raleigh, NC, U.S.A
NAFRAC. 2019. QoI Working Group of NAFRAC. North American Fungicide Resistance Action Committee. https://www.frac.info/contacts/frac-regional/ na-frac/qoi-fungicides

Olaya, G., and Koller, W. 1999. Diversity of kresoxim-methyl sensitivities in baseline populations of Venturia inaequalis. Pestic. Sci. 55:1083-1088.

Pasche, J. S., and Gudmestad, N. C. 2008. Prevalence, competitive fitness and impact of the F129L mutation in Alternaria solani from the United States. Crop Prot. 27:427-435

Pasche, J. S., Piche, L. M., and Gudmestad, N. C. 2005. Effect of the F129L mutation in Alternaria solani on fungicides affecting mitochondrial respiration. Plant Dis. 89:269-278.

Pfeufer, E. E., and Ngugi, H. K. 2012. Orchard factors associated with resistance and cross resistance to sterol demethylation inhibitor fungicides in populations of Venturia inaequalis from Pennsylvania. Phytopathology 102:272-282

Price, P. P., III, Purvis, M. A., Cai, G., Padgett, G. B., Robertson, C. L., Schneider, R. W., and Albu, S. 2015. Fungicide resistance in Cercospora kikuchii, a soybean pathogen. Plant Dis. 99:1596-1603.

Rosenzweig, N., Olaya, G., Atallah, Z. K., Cleere, S., Stanger, C., and Stevenson, W. R. 2008. Monitoring and tracking changes in sensitivity to azoxystrobin fungicide in Alternaria solani in Wisconsin. Plant Dis. 92:555-560.

Secor, G. A., Rivera, V. V., Khan, M. F. R., and Gudmestad, N. C. 2010 Monitoring fungicide sensitivity of Cercospora beticola of sugar beet for disease management decisions. Plant Dis. 94:1272-1282.

Seebold, K. W. 2008. Evaluation of fungicides for management of target spot on burley tobacco, 2007. Plant Dis. Manage. Rep. 2:FC099. https://www. plantmanagementnetwork.org/pub/trial/PDMR/volume2/abstracts/FC099.asp

Seebold, K. W. and Henderson, J. A. 2010. Evaluation of Quadris at different timings for control of target spot on burley tobacco, 2009. Plant Dis. Manage. Rep. 4:FC065. https://www.plantmanagementnetwork.org/pub/trial/ PDMR/volume4/abstracts/FC65.asp

Seebold, K. W. and Palmer, G. K. 2007. Evaluation of Quadris for control of target spot on burley tobacco, 2006. Plant Dis. Manage. Rep. 1:FC117. http://www.plantmanagementnetwork.org/pub/trial/pdmr/volume1/abstracts/ fc117.asp

Seebold, K. W. and Sizemore, P. L. 2011. Effect of application rate on the efficacy of Quadris against target spot on burley tobacco, 2010. Plant Dis. Manage. Rep. 5:V178. https://www.plantmanagementnetwork.org/pub/trial/PDMR/volume5/ abstracts/V178.asp

Sierotzki, H., Frey, R., Wullschleger, J., Palermo, S., Karlin, S., Godwin, J., and Gisi, U. 2007. Cytochrome $b$ gene sequence and structure of Pyrenophora teres and P. tritici-repentis and implications for QoI resistance. Pest Manage. Sci. 63:225-233

Smith, F. D., Parker, D. M., and Köller, W. 1991. Sensitivity distribution of Venturia inaequalis to the sterol demethylation inhibitor flusilazole: Baseline sensitivity and implications for resistance monitoring. Phytopathology 81: 392-396.

Standish, J. R., Tomaso-Peterson, M., Allen, T. W., Sabanadzovic, S., and Aboughanem-Sabanadzovic, N. 2015. Occurrence of QoI fungicide resistance in Cercospora sojina from Mississippi soybean. Plant Dis. 99:1347-1352.

Thiessen, L. 2018. Managing diseases. Chapter 8 in: 2018 Flue-Cured Tobacco Guide. North Carolina State University Extension Publication AG-187. https://tobacco.ces.ncsu.edu/wp-content/uploads/2019/01/2018-Flue-cured_lowres.pdf

USDA-NASS. 2018. Crop Values 2017 Summary. United States Department of Agriculture-National Agricultural Statistics Service. https://downloads. usda.library.cornell.edu/usda-esmis/files/k35694332/7h149s08f/qz20sv884/ CropValuSu-02-23-2018.pdf

Vaghefi, N., Hay, F. S., Kikkert, J. R., and Pethybridge, S. J. 2016. Genotypic diversity and resistance to azoxystrobin of Cercospora beticola on processing table beet in New York. Plant Dis. 100:1466-1473.

Vincelli, P., and Dixon, E. 2002. Resistance to QoI (strobilurin-like) fungicides in isolates of Pyricularia grisea from perennial ryegrass. Plant Dis. 86:235-240.

Zeng, F., Arnao, E., Zhang, G., Olaya, G., Wullschleger, J., Sierotzki, H., Ming, R., Bluhm, B. H., Bond, J. P., Fakhoury, A. M., and Bradley, C. A. 2015 Characterization of quinone outside inhibitor fungicide resistance in Cercospora sojina and development of diagnostic tools for its identification. Plant Dis. 99:544-550.

Zhang, G., and Bradley, C. A. 2017. Comparison of quinone outside inhibitor fungicide-resistant and-sensitive isolates of Cercospora sojina. Crop Prot. 94:59-63

Zhang, G., Pedersen, D. K., Phillips, D. V., and Bradley, C. A. 2012. Sensitivity of Cercospora sojina isolates to quinone outside inhibitor fungicides. Crop Prot. 40:63-68. 